\title{
Una propuesta de categorización de los rasgos variables de la orientación en narraciones de experiencia personal
}

\author{
Silvana Guerrero González* \\ Universidad de Chile y Pontificia Universidad Católica de Chile
}

\section{ANTECEDENTES FUNDAMENTALES ${ }^{1}$}

En el último tiempo, múltiples trabajos han puesto de relieve que la variación puede darse también en el proceso de construcción del discurso (cf. SilvaCorvalán 2001, López Morales 2004 y Moreno Fernández 2009). Así, los estudios han abordado temas como la variación sociolingüística en el empleo de los marcadores discursivos y el discurso referido en distintas comunidades del ámbito hispánico, pero las investigaciones que se han centrado en el nivel de la construcción de superestructuras discursivas son escasas (ver más adelante). Por consiguiente, en este trabajo seguimos la propuesta de Guerrero (2013) acerca de la posibilidad de aplicar los conceptos fundamentales de la sociolingüística variacionista de Labov (1983 [1972]) al plano del discurso, en particular, al del discurso narrativo. En dicho trabajo, hemos sugerido que

\footnotetext{
Para correspondencia, dirigirse a: Silvana Guerrero González (siguerrero@u.uchile.cl), Universidad de Chile, Facultad de Filosofía y Humanidades, Departamento de Lingüística, Av. Capitán Ignacio Carrera Pinto 1025, Ñuñoa, Santiago, Chile.

Los contenidos de esta nota corresponden a una sección del constructo analítico de nuestra tesis doctoral "Variación discursiva en narraciones de experiencia personal en el español hablado en Santiago de Chile", en preparación.
} 
una investigación con base en la variación de la superestructura discursiva de la narración de experiencia personal implica no incluir el concepto de regla variable en su sentido estricto. En consecuencia, insistiremos en que el mencionado concepto era pertinente para los trabajos realizados en los setenta y que, por lo tanto, en lo que respecta a la construcción discursiva es más adecuado hablar de cuantificación en términos generales. Asimismo, hemos puesto de relieve que en lugar de proponer una formalización previa de la estructura del discurso e ir comprobando cómo se ajustan a ella los datos concretos (Moreno Fernández 2009), existe también la posibilidad de construir una matriz de análisis que se desprenda, al menos en una parte importante, de los discursos de los propios sujetos, de manera que, posteriormente, pueda correlacionarse con los factores sociales en estudio, de acuerdo con los presupuestos del variacionismo laboviano.

En este orden, no estamos negando la existencia de formalizaciones discursivas tan difundidas como la estructura de la narración de experiencia personal de Labov y Waletzky (1967) y Labov (1972), muy útil en tanto constructo teórico-metodológico. Sin embargo, consideramos que también es relevante no solo trabajar con propuestas a priori, sino con una que se desprenda del análisis de datos concretos, con los resguardos necesarios para evitar nociones erradas centradas en cómo debería ser una narración de experiencia personal, y no de cómo es en el habla efectivamente emitida por los informantes. En consecuencia, recomendamos trabajar sobre la base de los comportamientos variables de los sujetos.

En consideración de lo anterior, en esta nota nos proponemos, por un lado, ofrecer una reflexión acerca de la aplicación del concepto de variación al plano discursivo y, por otro, hacer una propuesta concreta sobre los rasgos variables del componente orientacional de la narración de experiencia personal que pueden cuantificarse $\mathrm{y}$, por consiguiente, correlacionarse con factores del contexto social.

\section{LA VARIACIÓN PRAGMÁTICO-DISCURSIVA Y SU APLICACIÓN AL DISCURSO NARRATIVO}

Como señaláramos en nuestro trabajo de 2013, la variación a nivel pragmático-discursivo, en general, no aparece tratada en todos los manuales de sociolingüística. Sin ir más lejos, Moreno Fernández (2009) la incluye, aunque no la edición del mismo libro de 1998. Silva-Corvalán (2001) también incorpora un capítulo sobre el análisis del discurso en sociolingüística. 
El primer autor alude a los estudios sobre narración y su relevancia en la sociolingüística, asumiendo el modelo clásico de Labov y Waletzky (1967). Silva-Corvalán (1983 y 2001), por su parte, analiza los tiempos verbales, también basándose en la propuesta general de partes de la estructura narrativa laboviana. A nuestro juicio, lo esencial sería incorporar una metodología concreta, quizás diferente para cada comunidad de habla y pensada en términos cuantitativos generales, para emprender estudios cuyo foco sea el de la perspectiva variacionista aplicada a la construcción de superestructuras discursivas.

Otros ejemplos clásicos de estudios de variación a nivel de discurso son aquellos que se basan en las formas de tratamiento, en la conversación cotidiana (saludos, presentaciones, agradecimientos o despedidas), en los marcadores del discurso y en los clíticos discursivos. López Morales (2004: 161) señala que "las relaciones de ciertos aspectos del discurso con factores sociales presenta hoy un abanico de realidades muy notable". Así, el investigador destaca trabajos sobre marcadores del discurso y otros que denomina más "polifacéticos" que se vinculan, por ejemplo, con las modalidades discursivas argumentativas, narrativas y descriptivas, y con aspectos de coherencia y cohesión. Reyes (1996) se situaría dentro de estos análisis polifacéticos, cuando analiza las estrategias narrativas y su correlación con las variables sexo y nivel sociocultural de hablantes mexicanos en Monterrey, donde se parte de la base de los postulados labovianos de la estructura narrativa y se llega a una propuesta de constituyentes esenciales de la narración. En definitiva, de este grupo de trabajos, solo el de Reyes (1996) responde a una postura personal de análisis.

En el caso del español de Chile, contamos con investigaciones cuyo foco es la variación discursiva; es lo que ocurre, por ejemplo, con el trabajo de Poblete (1998), Cepeda (1990), el de Prieto y San Martín (2002-2003), los de San Martín (2004-2005, 2011 y 2013), los de Guerrero (2011a y 2011b), el de Rojas et al. (2012) y el de San Martín y Guerrero (2013), entre otros que se han centrado en este nivel de análisis; no obstante, los que se sitúan en el ámbito de la narración de experiencia personal también han tomado como base categorías de análisis ya existentes y han intentando demostrar cómo se ajustan a ellas los datos concretos.

Como vemos, la posibilidad de plantear, para la construcción de narraciones, una propuesta de análisis con categorías establecidas inductivamente se transforma en una necesidad, ya que no siempre los planteamientos realizados sobre la base de otras realidades lingüísticas darán cuenta, en su totalidad, de los rasgos variables de una comunidad de habla particular. En el caso de la narración de experiencia personal, conocidas son las tipologías acerca de los recursos evaluativos y varios los estudios que 
han demostrado que la evaluación no se manifiesta de la misma manera en correlación con factores sociodemográficos (Labov 1972, Reilly et al. 1990, Shiro 2003, Jiménez 2006, entre otros). Sin embargo, en lo que respecta al componente orientacional del relato, se ha tendido a señalar que en las narraciones se precisan solamente unos personajes, un tiempo y un lugar donde acontecieron los hechos.

En este sentido, Soler (2004), acogiendo los postulados de Johnstone (1990) sobre la orientación extratemática, esto es, aquellas orientaciones que no son estrictamente necesarias dentro de la narración y que dan la sensación de más credibilidad y exactitud acerca de los sucesos relatados, propuso cinco elementos que corresponden a la orientación de la narración y que se manifestarían de manera variable. Dichos elementos son la especificación de lugar, la especificación de tiempo, la descripción de personajes, los nombres de lugares y los nombres de personas. Si bien nosotros consideramos que planteamientos como este nos permiten avanzar sobre la posibilidad de hacer estudios variacionistas en superestructuras discursivas, creemos que todavía es insuficiente y que hay mucho más que decir acerca de los recursos variables que forman parte de la orientación de la narración.

\section{EL DISCURSO NARRATIVO: DEFINICIÓN, ESTRUCTURA Y APROXIMACIONES}

Connelly y Clandinin (1990) enfatizan que el estudio de la narrativa es el estudio de la forma en que los seres humanos experimentan el mundo, por consiguiente, la narrativa es un modo de razonamiento y un modo de representación.

Dentro de las características de la narración de experiencia personal destacan que cuenten con una linealidad temporal o causalidad, la que implica que exista un orden lógico en la construcción del relato. No obstante, es evidente que siempre estará presente algún tipo de reajuste o adaptación (Camargo 2004). Del mismo modo, siguiendo la argumentación de Camargo -quien se basa en los presupuestos labovianos-, las narraciones orales se comportan de forma similar a las citas, pues lo que en ellas ocurre es una representación selectiva de acciones, en la que algunos hechos se enfatizan y otros se suprimen por razones vinculadas con la memoria, la motivación, la situación comunicativa o con la imagen que se quiera proyectar de los acontecimientos, sea de uno mismo o de otros protagonistas de la historia. 
Otro rasgo de los relatos es el punto de vista, cuyas implicancias son que al tratar de comprender cómo la experiencia se transfiere del narrador al receptor, surge el punto de vista particular o punto de vista, desde el cual se observa la acción; por lo tanto, en las cláusulas narrativas es el dominio espacio-temporal en el que la información transmitida por la cláusula se podría interpretar por un entrevistador. Finalmente, en las narraciones encontraremos hechos objetivos y hechos subjetivos. Los primeros son aquellos que conoce el narrador, a través de la experiencia sensible, en tanto que un acontecimiento subjetivo es aquel que el narrador obtiene por la memoria, la reacción emocional o la sensación interna (Labov 1997).

De acuerdo con lo anterior, podríamos precisar, siguiendo a Adam y Lorda (1999), que

relatar, sea cual sea la situación narrativa, y ya se trate de experiencias vividas soñadas o imaginadas, constituye uno de los medios más eficaces de relacionarse con otras personas, por lo que es una actividad fundamental para la sociabilidad $[\ldots]$ todo relato constituye de algún modo un medio para reflexionar sobre las vivencias de las personas y para reordenarlas. El relato interroga en profundidad el actuar humano, sus motivaciones, sus objetivos, su ética [...] (Adam y Lorda 1999: 13 -14).

La narración es el tipo de secuencia discursiva que ha generado el mayor número de estudios, análisis y reflexiones. Las narraciones de experiencias personales constituyen una de las formas de expresión verbal más utilizadas por las personas; ficciones o relatos reales conforman una parte muy relevante de la totalidad de discursos que puede "consumir" una persona durante su vida (Bassols y Torrent 2003: 169). Las narraciones llenan nuestras horas de ocio desde la infancia y, además, invaden nuestra actividad comunicativa cotidiana. Para estas autoras existen los siguientes elementos comunes o universales de la narración (op. cit.: 171 y ss.):

1. Actor fijo: habrá al menos un actor estable a lo largo de la secuencia narrativa, lo que favorece la unidad de acción ${ }^{2}$. Asimismo, este actor estable debe transformarse durante la secuencia.

\footnotetext{
2 Según Aristóteles, para que haya relato debe haber unidad de acción, es decir, no basta con que haya una sucesión de acciones en un relato, sino que su encadenamiento debe ser cronológico, esto es, debe existir entre ellas una relación de causalidad para que formen un todo con comienzo, medio y fin (Adam y Lorda 1999: 104).
} 
2. Proceso orientado y complicado: toda narración incluye una sucesión mínima de acontecimientos caracterizados por su orientación hacia un final y su complicación. La orientación hacia un final implica un carácter temporal y una integración. Sin embargo, el orden de los acontecimientos del relato puede ser diferente del orden de los acontecimientos de la historia mientras aparezcan integrados, esto es, que muestren unidad de acción y orienten hacia un final. Además debe existir una complicación o problematización; no es un proceso rutinario el que da lugar a una narración, aunque incluya un conjunto de acciones vinculadas por la lógica de causa-efecto, sino que la sucesión de acontecimientos debe ser alterada por algún hecho inesperado que provoque una desviación en el curso normal de las cosas.

3. Evaluación: es presentada como una de las claves de la especificidad de la narración y el motor que genera el relato. Es su punto de partida y le da sentido a la narración.

Es el segundo tipo de elementos el que se transformará en la base de nuestra propuesta, esto es, aquel que se enfoca en el componente orientacional de la narración, lo que van Dijk (2000) denomina marco, es decir, las circunstancias en las que se producen los sucesos. Como queda de manifiesto, la orientación siempre alude a un carácter temporal, pero no se refiere a otros elementos que también desempeñan este rol en la cadena narrativa. En consecuencia, hemos decidido proponer una tipología de elementos variables que son parte de la orientación de la narración y que, en la medida en que se presenten de manera variable, podrán cuantificarse y correlacionarse con los factores del contexto social.

\subsection{La PROPUesta de Labov y Waletzky (1967) y Labov (1972) EN TORNO A LA NARRACIÓN DE EXPERIENCIA PERSONAL Y LA ORIENTACIÓN}

La bibliografía sobre narraciones es extensa; no obstante, tanto el trabajo seminal de Labov y Waletzky (1967), así como el de Labov (1972) han demostrado ser por mucho el modelo de más alto rendimiento empírico en las investigaciones sobre el problema. Labov (1972: 360) define la narración como "one method of recapitulating past experience by matching a verbal sequence of clauses to the sequence of events which (it is inferred) actually occurred [un método de recapitulación de la experiencia pasada adecuando una secuencia verbal de proposiciones a la secuencia de sucesos que (se supone) ocurrieron realmente (traducción nuestra)]". 
La narración es considerada como un texto que expresa una serie de eventos que ocurren en el tiempo, pero donde, a su vez, se percibe de manera subyacente una relación causal o temática. Labov y Waletzky (1967) y Labov (1972) distinguen dos tipos de relatos: los relatos mínimos, compuestos de -al menos- dos cláusulas narrativas en pasado y los relatos completos. Dichos autores plantean que una narración de experiencias personales plenamente formada, esto es, un relato completo, exhibe seis rasgos estructurales bien definidos. La base de esta propuesta se encuentra en el análisis realizado por Labov de relatos orales de experiencias personales en el marco de entrevistas que llevó a cabo en una comunidad de hablantes de la ciudad de Nueva York, cuyo enfoque fue denominado relatos de experiencias personales. Un relato de la experiencia personal es un informe de una secuencia de eventos que forman parte de la biografía del narrador. Esta definición separa la narrativa de otras formas de narrar una historia o relato del pasado que implique, por ejemplo, observaciones de acontecimientos. Se trata, según Labov (1997), de una segregación arbitraria en un sentido de la narrativa para fines técnicos, pero se demuestra que es totalmente pertinente, pues los acontecimientos que han entrado en la biografía y en la memoria de los hablantes son emocional y socialmente evaluados, transformándose en experiencias dignas de contarse. Dentro de esta perspectiva, se proponía describir la estructura semántica profunda invariante de los relatos, relacionándola con las diferencias superficiales ocasionadas por las características sociales de los hablantes. Así, Labov destaca que algunas narraciones están "completas", es decir, están conformadas por un comienzo, una parte central y un final. Asimismo, cabe señalar que estos componentes estructurales tienen una posición característica en la narración.

Como ya señalamos, los autores plantean que una narración de experiencias personales plenamente formada exhibe seis rasgos estructurales bien definidos, a saber, el resumen, la orientación, la complicación de la acción, la evaluación, la resolución y la coda, cada uno con una posición característica en la narración. Uno de los rasgos que nosotros consideramos esencial para realizar estudios sobre variación discursiva es la orientación, definida como sigue:

Orientación: una narración prototípica comienza haciendo referencia a un tiempo, un lugar, unas personas y una conducta esperada en cierta situación. Esos son los componentes de una orientación narrativa (adaptado de Labov y Waletzky 1967).

Considérese el siguiente segmento de una narración de experiencia personal del corpus del grupo de Estudio Sociolingüístico del Español de Chile 
(ESECH). Hemos distinguido con un sistema de etiquetas de inicio $<>$ y de cierre $<>>$ el componente orientacional, que se ubica luego del resumen.

a. I: la verdad que/ dos / dos situaciones peligro grande que tuve fue $<$ resumen $>$ la primera cuando me asaltaron en la casa $</$ resumen $>$

b. E: ya/ ¿cómo fue eso?

c. I: <orientación $>$ entraron dos tipos

d. yo estaba con mi hijo

e. E: ¿grande?

f. I: que estaba enfermo/no/ tenía como tres años

g. E: ah ya

h. I: y él estaba resfriado

i. estaba en cama

j. y era un día/ hacía frío y yo estaba al lado de él/ viéndolo y eso </ orientación $>(\ldots)(\mathrm{M} 125)$.

En este ejemplo se observa con claridad que hay orientaciones que si bien no son estrictamente necesarias en la cadena narrativa, sí serán fundamentales para entender por qué lo que se procederá a narrar corresponde a una historia digna de contarse (reportable). Primero se señala que se trata de "dos" sujetos que entran a la casa y luego la narradora cuenta que ella estaba con su hijo. En ambos casos se busca precisar quiénes son los personajes de la historia. En lo que sigue se describe al hijo: "estaba enfermo", "tenía como tres años", "estaba resfriado"; sin embargo, no podríamos decir que estas tres características corresponden al mismo nivel de especificidad, porque que haya estado enfermo (resfriado) no es una característica equivalente a señalar su edad, que es un rasgo más concreto todavía y que se vincula con un tiempo específico. Lo mismo ocurre con "estaba en cama", que corresponde más bien a un lugar específico dentro de la casa. Finalmente, la narradora proporciona una caracterización del tiempo ("hacía frío") y termina dando cuenta de su posición espacial en la historia ("yo estaba al lado de él"). En la medida en que algunos informantes de una comunidad de habla incorporen o no incorporen este nivel de detalle en la orientación de sus narraciones, podemos sugerir que se trata de rasgos que se van a presentar de manera variable y que, en consecuencia, podrán cuantificarse y correlacionarse con los factores sociales. De hecho, muy probablemente, no todos los hablantes los incluirán a medida que narran. Nosotros argüimos que es en las diferencias superficiales donde está la diferencia, pues la narradora podría haber sido más sintética y haberse limitado a decir "estábamos con mi hijo en la casa y entraron dos tipos". 


\section{LA PROPUESTA}

Labov y Waletzky (1967) y Labov (1972) plantean que en la orientación de una narración se hace referencia a un tiempo, un lugar, unas personas y una conducta esperada en cierta situación. Más tarde, Soler (2004), siguiendo a Johnstone (1990), atribuirá categorías más específicas a la propuesta laboviana, a saber, la especificación de lugar, la especificación de tiempo, la descripción de personajes, los nombres de lugares y los nombres de personas. Sin embargo, nosotros consideramos que estos elementos no son suficientes para dar cuenta de todas las categorías orientacionales que se explicitan en las narraciones de experiencia personal. Asimismo, la ausencia de definiciones en las categorías que emplean los autores recién citados causa confusión al momento de intentar aplicarlas en un análisis de narraciones concretas, pues, aunque la mayoría de ellas parece transparente, podríamos preguntarnos cuál es la diferencia entre lo que Soler (2004) denomina "descripción de personajes" y lo que Shiro (2003) llama "estado físico" de los personajes respecto del componente evaluativo de la historia. ¿La diferencia es acaso que uno es objetivo (orienta) y el otro subjetivo (evalúa)? En nuestra opinión, dichas delimitaciones conceptuales en las categorías variables de la narración, que hasta ahora se han analizado, no quedan claras. Asimismo, hemos observado que las narraciones no siempre son acerca de unos personajes, sino que hay ocasiones en las que el énfasis está puesto en la relación entre un personaje y un objeto, y este último es también protagonista de la historia. Por esta razón, y haciéndonos eco de lo que Moreno Fernández (2012) señala sobre los discursos narrativos, esto es, que los mencionados discursos construyen una realidad manejando elementos que acrediten lo narrado y otorgan detalles en la medida en que el interlocutor lo requiera, hemos optado por desarrollar una propuesta que incluye nueve categorías de orientación. Dicha tipología se construyó y ejemplificó con base en la lectura de una muestra de 192 narraciones de experiencia personal extraídas del corpus ESECH.

1. Especificación de tiempo: en el relato se incluye información temporal de época, año, día, hora o estación temporal en donde ocurren los hechos, o especificación de tramos de tiempo entre un suceso y otro del relato. Responde a la pregunta "¿Cuándo acontecieron los hechos?", por ejemplo, "cuando estaba en la básica, estaba en cuarto año básico" (H023). 
2. Especificación de lugar: en la narración se incorporan datos sobre el espacio físico en donde acontecen los sucesos. Responde a la pregunta “¿Dónde acontecieron los hechos?”, por ejemplo, "bajamos a lavar ropa a un río" (H054).

3. Nombres propios de lugares: en la narración se incluyen nombres propios del lugar o los lugares en donde acontecen los hechos, por ejemplo, "que estaban en Talagante" (M121).

4. Descripción objetiva de lugar: el narrador incorpora en su relato características objetivas del lugar o los lugares donde transcurren los hechos. Responde a la pregunta "¿Cómo era el lugar donde acontecieron los hechos"?, por ejemplo, "era una pendiente más o menos pronunciada para poder subir" (H097).

5. Especificación de personajes: en la narración se anuncian de manera explícita los personajes involucrados en la historia. Responde a la pregunta "¿Quién o quiénes estuvieron involucrados en los hechos?", por ejemplo, "venía con mi polola" (H001).

6. Nombres propios de personajes: en el relato se incorporan nombres propios de los personajes involucrados en la historia y con ello se otorga mayor especificidad a lo narrador, por ejemplo, "el señor Cubillos" (H083).

7. Descripción objetiva de personajes: el narrador da cuenta de características físicas o de descripciones no evaluativas de los personajes. Se incluyen también estados de los personajes, por ejemplo, "y eso que teníamos quince años" (M171).

8. Descripción de la situación: en la narración se alude al contexto general donde acontecen los hechos, a las circunstancias o al escenario global, por ejemplo, "y yo lo tenía como al frente" (H146).

9. Descripción de objetos: el narrador incluye datos objetivos de los objetos presentes en el relato, en especial, cuando estos cobran protagonismo en los sucesos, por ejemplo, "era una silla sin ruedas" (M188).

De este modo, queda demostrado que una investigación centrada en la variación sociolingüística de la construcción discursiva de la narración de experiencia personal no solamente puede realizarse aplicando constructos teóricos-metodológicos preexistentes y generales, sino que también es una opción metodológica válida realizar un análisis inductivo y verificar cómo 
varían ciertos elementos discursivos según lo que la misma comunidad de habla construye en términos narrativos.

\section{REFLEXIONES FINALES}

En el marco de lo que Moreno Fernández (2012) denomina sociolingüística post-laboviana, cuya base no es desconocer la propuesta original de Labov (1983 [1972]), sino demostrar que la disciplina ha derivado hacia ámbitos de interés diferentes de los que preocupaban en sociolingüística durante los años setenta, como la variación en el nivel sintáctico y discursivo, la riqueza estilística o el manejo de factores pragmáticos, nosotros consideramos pertinente ofrecer una tipología específica sobre los rasgos variables que pueden cuantificarse en la orientación de la estructura narrativa (Labov y Waletzky 1967 y Labov 1972). Si estos y otros elementos que el investigador considere pertinentes pueden variar, podrán, a su vez, cuantificarse, sin siquiera hacer alusión a los conceptos de variable y variantes lingüísticas en tanto constituyentes de una regla variable. Por lo tanto, puede verificarse si ciertos rasgos se presentan o no de manera variable en las construcciones discursivas de los hablantes, en correlación con sus factores sociales, sin que se trate de formas alternantes de decir lo mismo.

En definitiva, los trabajos empíricos sobre el problema han demostrado que la variación no se da en la estructuración de la narración, sino que la diferencia se presenta en el nivel de detalle. Como señala Labov (1972), mientras la estructura semántica profunda de los relatos es invariante, se puede vincular la variación con las diferencias superficiales ocasionadas por las características sociales de los hablantes. Por años, estos "detalles" se han referido exclusivamente a las múltiples formas de "evaluar" lo que se está narrando, pero son casi inexistentes los trabajos que han demostrado que también puede variar la información que corresponde a la orientación de la cadena narrativa.

Si, como plantea Moreno Fernández (2012), la construcción del discurso se realiza a través de un proceso selectivo capaz de proyectar una representación de mundo, también podríamos pensar que en la construcción del relato se puede mostrar un "estilo" discursivo, en términos de lo que Coupland (2007) define como una forma de hacer algo, que, a su vez, se podría vincular con la construcción de la identidad de los hablantes. Sin duda, aproximaciones de este tipo contribuyen al desarrollo de la disciplina y comenzar por determinar cuáles son estos recursos variables nos parece 
lo más pertinente, aunque, en nuestro caso, haya sido en un ámbito muy particular: el de la orientación de la estructura de la narración de experiencia personal.

Por último, nos parece adecuado citar a Labov (1983), quien ya había puesto de relieve lo que nosotros hemos querido destacar:

Si queremos aprehender el lenguaje tenemos que examinar los datos del habla cotidiana lo más detallada y directamente posible, y caracterizar su relación con nuestras teorías gramaticales con la mayor precisión posible, corrigiendo y ajustando la teoría con el fin de que se adecúe al objeto de estudio (Labov 1983: 256).

La propuesta de categorización de los rasgos variables de la orientación en narraciones de experiencia personal que hemos presentado constituye, indudablemente, una forma de adaptación de la teoría sociolingüística para su aplicación al análisis variacionista del discurso.

\section{REFERENCIAS BIBLIOGRÁFICAS}

Adam, Jean-Michel y Clara-Ubaldina Lorda. 1999. Lingüística de los textos narrativos. Barcelona: Ariel.

Bassols, Margarida y Ana Torrent. 2003. Modelos textuales. Barcelona: Eumo-Octaedro.

Camargo Fernández, Laura. 2004. La Representación del Discurso en la Narración Oral Conversacional. Estudio Sociopragmático. Tesis doctoral. Madrid: Universidad de Alcalá.

Cepeda, Gladys. 1990. La variación de/s/ en Valdivia: sexo y edad. Hispania 73(1): 232-237.

Connelly, Michael y D. Jean Clandinin. 1990. Stories of experience and narrative inquiry. Educational Researcher 19(5): 2-14.

Coupland, Nikolas. 2007. Style: Language variation and identity. Cambridge: Cambridge University Press.

Guerrero, Silvana. 2011a. Diferencias de género en evaluaciones de narraciones de experiencia personales en el habla juvenil de Santiago de Chile. Una aproximación sociolingüística. Revista Signos. Estudios de Lingüística 44(75): 18-32.

2011b. Análisis sociolingüístico de las diferencias de género en patrones narrativos de historia de experiencia personal en el habla juvenil de Santiago de Chile. Boletín de Filología XLVI(2): 85-106.

2013. Sobre la aplicación de la perspectiva sociolingüística al estudio de la variación discursiva: el caso de la narración de experiencia personal. Onomázein 28: $188-200$.

JimÉnEZ, TeIRA. 2006. La narración infantil. Un estudio en niños de educación básica. Revista de Investigación 60: 157-174.

Johnstone, Barbara. 1990. Variation in discourse: Midwestern narrative style. American Speech 65(3): 195-214. 
Labov, William. 1972. The transformation of experience in narrative syntax. En Language in the inner city. Studies in the Black English Vernacular. Philadelphia: University of Pennsylvania Press.

1983 [1972]. Modelos Sociolingüísticos. Madrid: Cátedra.

1997. Some further steps in narrative analysis. Journal of Narrative and Life History 7: 395- 415.

Labov, William y Josua Waletzky. 1967. Narrative analysis. En Jane Helm (ed.). Essays on the verbal and visual arts, pp. 12-44. Seattle: University of Washington Press.

López Morales, Humberto. 2004. La investigación sociolingüística en Hispanoamérica durante los últimos años. Lingüistica Española Actual XXVI(2): 151-173.

Moreno Fernández, Francisco. 1998. Principios de sociolingüística y sociología del lenguaje. 1. ${ }^{\mathrm{a}}$ ed. Barcelona: Ariel.

2009. Principios de sociolingüística y sociología del lenguaje. 4. ${ }^{\mathrm{a}}$ ed. Barcelona: Ariel.

2012. Sociolingüistica cognitiva. Proposiciones, escolios y debates. Madrid: Iberoamericana/Vervuert.

Poblete, María Teresa. 1998. Los marcadores discursivo-conversacionales de más alta frecuencia en el español de Valdivia (Chile). Estudios Filológicos 33: 93-103.

Prieto, Luis y Abelardo San Martín. 2002-2003. Diferencias de género en el empleo del discurso referido: aproximación sociolingüística y pragmático-discursiva. Boletín de Filología XXXIX: 269-303.

Reilly, Judy, Edward S. Klima y Ursula Bellugi. 1990. One more with feeling: affect and language in atypical populations. Development and Psychopathology 2: 367-391.

Reyes, Claudia. 1996. Estrategias narrativas en la zona metropolitana de Monterrey. En Dora Rodríguez Flores y Lidia Rodríguez Alfano (eds.). Lenguaje y sociedad: Metodología y análisis aplicados a El habla de Monterrey, pp. 101-120. México: Trillas.

Rojas, Cristian, Alejandra Rubio, Abelardo San Martín y Silvana Guerrero. 2012. Análisis pragmático y sociolingüístico de los marcadores discursivos de reformulación en el habla de Santiago de Chile. Lenguas Modernas 40: 103-123.

San Martín, Abelardo. 2004-2005. Igual como marcador discursivo en el habla de Santiago de Chile: función pragmático-discursiva y estratificación social de su empleo. Boletín de Filología XL: 201-232.

2011. Los marcadores interrogativos de control de contacto en el corpus PRESEEA de Santiago de Chile. Boletín de Filología XLVI(2): 135-166.

2013. Los reformuladores de distanciamiento en el corpus PRESEEA de Santiago de Chile. Boletín de Filología XLVIII(1): 171-199.

San Martín, Abelardo y Silvana Guerrero. 2013. Una aproximación sociolingüística al empleo del discurso referido en el corpus PRESEEA de Santiago de Chile. Revista Signos. Estudios de Lingüística 46(82): 258-282.

Shiro, Martha. 2003. Genre and Evaluation in Narrative Development. Journal of Child Language 30: 165-195.

Silva-Corvalán, Carmen. 1983. Tense and aspect in oral Spanish narrative: context and meaning. Language 59(4): 760-780.

2001. Sociolingüistica y pragmática del español. Washington: Georgetown University Press.

Soler, Sandra. 2004. Discurso y género en historias de vida. Una investigación de relatos de hombres y mujeres en Bogotá. Bogotá: Publicaciones del Instituto Caro y Cuervo.

van DiJK, Teun. 2000. La ciencia del texto. Barcelona/Buenos Aires: Paidós. 